\title{
Criterios de inaplicabilidad de la Circular Reglamentaria 002 de 2015 proferida por la Unidad Administrativa Especial de la Aeronáutica Civil (UAEAC) en la agricultura de precisión y otras aplicaciones ambientales y geográficas
}

\author{
Mauricio Álvarez de León ${ }^{1 *}$, Jessica Lorena Valencia-Murillo ${ }^{2 *}$ \\ 1 MVZ,MSc; \\ 2 Abogado \\ * Corporación Colombiana de Investigación Agropecuaria - AGROSAVIA. Centro de Investigación La Libertad, Km 17 vía a \\ Puerto López, Villavicencio - Meta - Colombia. \\ Email: malvarez@agrosavia.co
}

Recibido: 29 de marzo de 2017

Aceptado: 14 de agosto de 2017

\begin{abstract}
Los autores analizan la Circular No. 002 de 2015 publicada en el diario oficial con el código CLI No. 49.624, del 03 de septiembre de 2015 y sustentan las razones de la inaplicabilidad de la norma por cuanto se considera ilegitima a luz de la Teoría del derecho por no cumplir con las características propias de una norma jurídica aplicable: justa, valida y eficaz; este último elemento carente en la Circular objeto de estudio, por cuanto no se adapta a todos los ámbitos de la actividad de las Ilamadas aeronaves pilotadas a distancia, representando un grave obstáculo para la introducción y práctica de la agricultura de precisión que tiene el potencial de hacer más rentable, competitivo y ambientalmente sostenible la producción agrícola en Colombia.
\end{abstract}

\section{Introducción}

En el preámbulo de la circular se citan las consideraciones que hace la $\mathrm{OACl}^{1}$ al respecto de la introducción, fabricación y uso de plataformas de vuelo de las comúnmente llamadas "drones" y se resalta que "La Organización de Aviación Civil Internacional, (OACI) considera que debido a que varios Estados de la Región Latinoamericana se encuentran fabricando aeronaves pilotadas a distancia $\left(R P A^{2}\right)$ y desarrollando sus marcos reglamentarios, el Sistema Regional de Cooperación para la Vigilancia de la Seguridad Operacional SRVSOP ${ }^{3}$, consciente que la Región debería adoptar un enfoque armonizado en cuanto a la elaboración de reglamentos, ha iniciado la planificación para el desarrollo de requisitos RPAS en los diferentes conjuntos $L A R^{4}$, para lo cual ha establecido un mapa de ruta por un plazo de 6 años (entre los años 2012 y 2018)". Y agrega

Acrónimo de Organización de Aviación Civil Internacional. RPA Acrónimo en inglés de Aeronave Remotamente Tripulada Sistema Regional de Cooperación Para la Vigilancia de la Seguridad Operacional.

4 LAR Reglamentos Aeronáuticos latinoamericanos. que "Sabe también la OACI que la integración nos llevará un buen tiempo, por lo que es necesario la colaboración, el conocimiento y la experiencia de los interesados", para ello confiere un plazo hasta el 2.018 para que los países armonicen la norma de acuerdo con sus particulares necesidades e involucrar esas tecnologías a los desarrollos nacionales.

A partir de lo anteriormente expuesto, se infiere que Colombia cuenta con tiempo suficiente para expedir una norma que regule las particularidades de la actividad de las llamadas aeronaves pilotadas a distancia, considerando su amplio y variado espectro de uso.

De otro lado, entre las obligaciones del estado Colombiano para lograr la armonización de los reglamentos aeronáuticos esta lo manifestado en LAR 11, en relación con las obligaciones derivadas del Reglamento Aeronáutico Latinoamericano "Reglas para el desarrollo, aprobación y enmienda de los LAR" en el que se establecen una serie de pasos que incluyen: a) Propuesta; b) Validación Interna; c) Difusión de la Propuesta; d) Análisis de comentarios y; e) Aprobación. 
De lo anterior se deduce que para efectuar alguna enmienda o modificación a los "Requisitos generales de aeronavegabilidad y operaciones para RPAS" contenidos en el numeral 4.25.8.2 del RAC "Otras operaciones $^{\prime \prime}$, su contenido debe ser presentado para conocimiento de cualquier persona natural o jurídica y que los comentarios o sugerencias que resulten pueden ser involucrados o rechazados, pero en cualquier caso se debe informar al autor de la sugerencia las razones en uno u otro sentido.

Así, la modificación del reglamento aeronáutico nacional deberá recoger las validas inquietudes y propuestas para la actividad de todos los sectores involucrados en la operación de plataformas aerotransportadas, que portan sensores remotos y proximales, como en la Agricultura de Precisión (AP) y en otras aplicaciones ambientales y geográficas, especialmente aquellas que se utilizan en investigación científica básica y aplicada y en la posterior vinculación a actividades comerciales.

En consecuencia se debe consultar a la academia, representada por las Universidades, a las organizaciones estatales como el IGAC, al Instituto de investigación de recursos biológicos Alexander Von Humboldt, al IDEAM, al ICA, a la Corporación Colombiana de Investigación Agropecuaria antes Corpoica ahora AGROSAVIA, a los institutos relacionados con el desarrollo rural y la asistencia técnica, para que aporten desde su particular visión orientada por su quehacer misional, a la construcción de una norma a la medida de las necesidades del sector agropecuario y ambiental.

Para las instituciones del sistema nacional de ciencia y tecnología agropecuaria es necesario analizar críticamente las normas que reglamentan el uso de las nuevas tecnologías, porque es su deber misional incorporar tecnologías e información al desarrollo tecnológico del Agro colombiano, como es el caso de las plataformas aerotransportadas de baja altura, que son utilizadas en lo que se conoce como Agricultura de Precisión (AP), que sirven para adquirir información en tiempo real de plagas y enfermedades, estimativos de cosechas, ordenamiento y gestión del territorio rural, para el monitoreo de superficies cultivadas y ambientes naturales y adicionalmente como soporte de sensores proximales para colectar información directa sobre la radiación fotosintéticamente activa, gases atmosféricos, esporas de hongos o microorganismos que se diseminan por el aire, en colectas de insectos sobre plantaciones y eventualmente son utilizadas para dispersión localizada de fertilizantes y agroquímicos, con

RAC Reglamento Aeronáutico Colombiano considerables beneficios económicos y ambientales y son la punta de una tecnología de lo que se conoce como aviación agrícola no tripulada, que requiere de propias normas y restricciones para que ella sea en definitiva un factor dinamizador del desarrollo rural.

\section{Conclusiones}

Se exponen a continuación los argumentos que explican porque la Circular 002 es inaplicable en la Agricultura de Precisión y se exponen las características especiales de la operación de una plataforma de vuelo para AP que la hacen disímil a una Aeronave Pilotada a Distancia (RPA) y por tanto su tratamiento debe ser especial y regulado de forma independiente:

1. Debe verificarse el alcance de la definición de Aeronave Pilotada a Distancia (RPA).

"Aeronave no tripulada que es pilotada desde una estación de pilotaje a distancia":

Esta definición que aparece en la circular introduce el concepto de "piloto" que ejerce control continuo sobre la aeronave en todas las fases de vuelo, lo cual en AP no es precisamente necesario, ni técnicamente viable.

La AP requiere del uso de un sistema de piloto automático permanente, como en el caso de las aplicaciones aerofotogramétricas que no utilizan imágenes individuales del terreno en su gestión, se requiere de mosaicos de imágenes georreferenciados y ortocorregidos los cuales solo pueden ser obtenidos mediante el traslape de imágenes individuales con hasta un $80 \%$ (Sidelap y endlap). Lo anterior no es alcanzable mediante el uso exclusivo del control manual de la plataforma, en esas circunstancias aparecen los autopilotos o pilotos automáticos que garantizan que la información obtenida del terreno por las imágenes pueden tener los estándares de calidad, en especial la precisión requerida, para la generación de mosaicos fotográficos tipo ortofotomapas. En forma semejante sucede para colección de insectos o esporas de hongos, donde se deben seguir patrones de vuelos precisos y regulares.

En ese sentido la plataforma se vuelve "Autónoma", por cuanto sigue estrictamente un plan de vuelo prediseñado, lo cual significa que no está fuera de control ni que actúa de forma anárquica. Todos y cada uno de los movimientos de la aeronave son seguidos por el operador en tierra mediante sistemas de radiocomunicación y telemetría y el apoyo de observadores avanzados en el campo, 
comunicados entre sí y con la estación de control en tierra.

Las restricciones al uso de los "Sistema de Piloto automático" en los RPA, contenida en la Circular 002 de 2015, en el sentido en que estos solo se usarían para asistir al piloto, para facilitar la estabilización o efectuar la recuperación del aparato en caso de ser necesario y que no puedan ser usados en todas las fases del vuelo es una grave restricción para el desarrollo de la AP.

Resulta difícil entender la anterior limitación, cuando en el ámbito aeronáutico un alto porcentaje del vuelo de las aeronaves comerciales de pasajeros que operan en el territorio nacional o en el extranjero es llevado a cabo en forma controlada por "pilotos automáticos" llegando incluso algunos de ellos a ejecutar despegues y aterrizajes, los pilotos son supervisores de los instrumentos y ellos pueden eventualmente tomar el control cuando las circunstancias así lo exija. El uso de estos autopilotos le confiere a la operación una mayor seguridad a la navegación aérea.

2. En Agricultura de precisión se considera que la persona en control de la plataforma no es un "piloto", es el operador de un sistema informático (Software) relacionado con una aplicación de misión de vuelo, ese operador tiene formación específica en el diseño, supervisión y ejecución de planes de vuelo y adicionalmente debe poseer habilidades en la operación de aeromodelos, en todas las fases del vuelo manual, que incluyen labores de despegue y aterrizaje (take off y landing) y maniobras que incluyen la intervención en casos de eventos fortuitos.

En AP, la toma de imágenes o la captura de otro tipos de información o datos así como la colección de especímenes, o la aspersión de diferentes productos, es llevada a cabo con el uso de mecanismos automáticos (Autopilot) lo cual le confiere a la plataforma requerida por la Agricultura de Precisión, una condición de operación autónoma, de manera que exigir al llamado "Piloto a distancial Observador" que acredite materias del curso en tierra de piloto privado de avión, es desconocer que aunque la operación de las plataformas de vuelo RPA tiene fundamentos aerodinámicos compartidos, los RPA tienen particularidades, aspectos diferenciantes que les son inherentes, por esa razón es que los centros de instrucción y las universidades con programas en ingeniería aeronáutica o asimilables deberían generar programas propios en términos y contenidos para la operación de los llamados RPA, es más, algunos de ellos pudieran incorporar los requerimientos de la AP, para alcanzar una capacitación consecuente con la aviación agrícola no tripulada y no una capacitación indiferenciada que no contribuye efectivamente a la cualificación de operadores aptos, competentes, capaces y confiables.

3. Las plataformas de vuelo utilizadas en AP desempeñan acciones para conocer de plagas, de enfermedades en las plantas, de deficiencias nutricionales, de infestaciones de malezas, aspectos de vulnerabilidad, riesgo de inundaciones y fuego y otros eventos que tienen comportamientos inciertos y frecuencias aleatorias dentro de los ciclos hidrometeoro lógicos, estas particularidades no son contempladas en la Circular 002 de UAEAC.

Es importante dar un tratamiento diferente a las actividades de las plataformas de vuelo en AP especialmente en lo referente a la "Solicitud de Autorización", que de acuerdo con la Circular 002 se debe presentar ante la Dirección de Servicios a la Navegación Aérea (DSNA) con una antelación de (15) días hábiles a la fecha prevista para el inicio del vuelo, la cual debe contener información tal como fecha del vuelo previsto, lugar de la operación, nivel de vuelo, ruta que ha de seguirse (plan de vuelo), duración del vuelo entre otros datos, información que puede resultar materialmente imposible de obtener cuando se trata de plagas y enfermedades y en eventos climáticos extremos. Ni las más sofisticadas estaciones meteorológicas del mundo proveen información con el nivel de certeza solicitado en la norma para garantizar un vuelo con un microclima ideal con quince (15) días de antelación como requiere la circular. Como si este trámite no fuera difícil y arduo, con la Solicitud de autorización que debe expedir la (DSNA) se debe solicitar adicionalmente otro permiso a la Fuerza Aérea Colombiana, cuando las actividades se encuentren relacionadas con la fotografía aérea.

Estos trámites pueden limitar severamente la acción de los productores rurales, cuando se deban tomar decisiones apoyados en plataformas aerotransportadas de baja altura en la Agricultura de precisión, decisiones que en muchos casos tienen repercusiones económicas, ambientales y sociales.

4. La Circular 002 en el numeral 7.6, literal (i) establece unas condiciones que de alguna manera facilitarían la investigación e innovación, mediante la cual establece que las entidades del estado y universi- 
dades, que sustenten que el uso de sus RPAS tiene un carácter de Investigación e Innovación, de interés nacional o que es fundamental para cumplir las funciones designadas por el Gobierno nacional a dichas entidades, podrán otorgárseles permisos que incluyan varios vuelos durante un periodo de tiempo establecido, previa evaluación, siempre y cuando se cumplan los requisitos establecidos en la circular.

Al respecto surgen algunas reflexiones, la primera es que la Investigación científica básica y aplicada que desarrolla la Corporación Colombiana de Investigación Agropecuaria antes Corpoica ahora AGROSAVIA, y en general las instituciones de investigación y las universidades está diseñada para que se exprese en resultados tecnológicos, esto es que se pueda transferir y que el saber científico sea puesto al servicio del país por medio de productos tecnológicos que sirvan a la agricultura y al desarrollo rural en general, para que la agricultura sea competitiva en los mercados internacionales, en los que tiene que intervenir y consecuentemente sea un factor para mejorar la calidad de vida de los productores rurales. Los resultados de la investigación deben ser transferibles, entregables y vinculados por usuarios tecnológicos, ellos son asistentes técnicos (profesionales y técnicos), los gremios de la producción, la academia, los campesinos y desde luego el corpus científico. Así las cosas ¿Qué sentido tiene que la UAEAC permita a AGROSAVIA adelantar una determinada investigación si finalmente no se puede transferir y vincular al sector agropecuario?

5. Uno de los postulados básicos de la AP, es que se percibe el territorio como heterogéneo, se reconoce que existe una variabilidad espacial de las propiedades físicas, químicas, microbiológicas y mineralógicas de los suelos que son el soporte de la agricultura, lo cual implica un manejo diferenciado de los ambientes productivos. Este concepto de pluralidad de ambientes incluso es acogido por la Constitución Política de Colombia, cuando manifiesta que Colombia es una nación que se reconoce a sí misma como mega diversa ${ }^{6}$.

$\mathrm{Al}$ reconocer la heterogeneidad del paisaje colombiano, las asimetrías en su desarrollo y los diferentes requerimientos de las regiones, la pregunta que surge es ¿Cuál es esa altura óptima y el rango de

6 Articulo 79 Constitución Política de Colombia: "Es deber del Estado proteger la diversidad e integridad del ambiente, conservar las áreas de especial importancia ecológica y fomentar la educación para el logro de estos fines". operación para captar los diferentes fenómenos que afectan la agricultura? ¿Quién puede suministrar esa información?, información que es relevante para el desarrollo de la AP. Reglamentar como en efecto lo hace la Circular 002 de la $\mathrm{UAEAC}^{7}$ con restricciones iguales para todo el territorio nacional es fuertemente limitante para el desarrollo de la AP, en regiones como los valles interandinos, las planicies amazónicas y orinocences, las áreas planas del caribe seco y húmedo, los altiplanos cundiboyacences y nariñense, donde las condiciones de geo forma, microclima y densidades de población son marcadamente diferentes.

Para establecer las posibles restricciones en la operación de los RPA en Colombia, teniendo en cuenta la diversidad de los paisajes geomorfológicos es necesario hacerlo sobre la base de la investigación básica local y regional, dirigida y coordinada entre instituciones especializadas en agricultura que pueden proponer alturas de vuelo y el rango de operaciones con base en la resolución de los sensores o instrumentos a bordo y lo que es más importante, atendiendo a la naturaleza de los fenómenos a describir. En ese sentido se plantea que la norma no se estructure sobre básicamente sobre consideraciones exclusivas de seguridad y defensa.

6. Enuncia la Circular 002 de la UAEAC que "en el país se ha venido presentando un interés importante por el uso de los RPAS, por lo que se han atendido reuniones con la Asociación de aeronaves remotamente tripuladas de Colombia, empresarios interesados, entidades gubernamentales y las diferentes Fuerzas Militares, así mismo se han recibido solicitudes de información, lo cual hace necesario aclarar y ampliar el alcance de los requisitos generales establecidos en el numeral 4.25.8.2 del RAC "Otras operaciones" para contribución de la seguridad aérea nacional."

Por lo menos en cuanto se refiere a la Corporación Colombiana de Investigación Agropecuaria antes Corpoica ahora AGROSAVIA, no se recibió invitación alguna para participar de reuniones preparatorias o conducentes a la elaboración de la Circular 002, a pesar de lo mencionado el oficio 5102.1092014054821 enviado por UAEAC a AGROSAVIA se advierte: "nos estaremos comunicando con ustedes para fijar una fecha de reunión". La circular

7.3. LIMITACIONES DE LA OPERACIÓN RPAS EN COLOMBIA, literales ( $f$ ) Volar a una altura superior a 500 pies (152 metros aproximadamente) sobre el terreno (AGL) o sobre el agua y el literal "(g) Volar de modo que se aleje más de 750 metros de distancia del operador o del lugar de su lanzamiento o despegue” 
reglamentaria aparece como un hecho cumplido que fue tratado en "reuniones con la Asociación de Aeronaves remotamente tripuladas de Colombia, empresarios interesados, entidades gubernamentales" donde se trató ampliamente el tema, reuniones de las que poco se sabe.

No se puede entender como la academia, las entidades gubernamentales y los interesados en la explotación comercial de lo que la UAEAC Ilama RPAS, habrían participado en la estructuración de la Circular reglamentaria 002 sin presentar objeciones como las que aquí se señalan y mucho menos que las posibles recomendaciones que eventualmente hayan podido aportar, no hubieran sido tenidas en cuenta al momento de redactar la norma, una norma como está la cual requiere de una arquitectura colectiva de construcción, ello es manifestado por la propia OACI y reforzado por el Sistema Regional de Cooperación para la Vigilancia de la Seguridad Operacional SRVSOP cuando reconoce que se trata de armonizar diferentes situaciones y aspectos por regular.

7. En el numeral 7.6 SOLICITUD DE AUTORIZACIÓN, se solicita un análisis sobre la actividad que pretende realizar, declarando que su operación no afecta a empresas de trabajos aéreos especiales certificadas, debido a que el vuelo que se pretende realizar no es factible o no puede ser realizado con una aeronave tripulada (con certificado de aeronavegabilidad) que efectué trabajos aéreos especiales. Con ello se pretende que el estudio en mención establezca que las plataformas aéreas que operan a baja altura y que portan sensores fotográficos no son competencia directa de las plataformas aerotransportadas convencionales cuando en realidad si lo son, en determinados escenarios y bajo algunas condiciones pueden llegar a ser complementarias e inclusive aventajarlas en otros escenarios en términos de costos, versatilidad y seguridad operacional.

En el ámbito aeronáutico a manera de ejemplo, se puede citar que se considera que el avión de combate Raptor F-22 puede ser el último avión de combate tripulado y a partir de allí se dará paso a las tecnologías de aeronaves no tripuladas, igual sucede en la industria automotriz y en otro sectores tecnológicos, las innovaciones han determinado que algunas tecnologías se tornen obsoletas, no significa esto en modo alguno, que los vuelos Aero fotogramétricos convencionales vayan a desaparecer en el corto plazo, significa que en determinadas condiciones en especial en lo relativo a la escala predial, las plataformas de vuelo autónomas o no tripuladas que operan a baja altura y con alta resolución son más eficientes y eficaces que las aeronaves de servicio Aero fotogramétrico y sobre todo más económicas.

En este orden de ideas, solicitar declaraciones para establecer que una tecnología no afecta a otra es rezagado y excluyente ¿Porque entonces no solicitarles a los consumidores de imágenes satelitales de diferentes resoluciones, que presenten estudios que certifiquen que dichas imágenes no pueden ser captadas por "empresas de trabajos aéreos especiales certificadas" en Colombia?

Una opción viable para las empresas de trabajos aéreos especiales es que se involucren en las nuevas tecnologías y aprovechen la experticia, los equipos y pilotos que poseen en un mercado de libre competencia y no obtener por la vía de una reglamentación una posición monopólica dominante en un mercado que seguramente tiene espacio para la calidad y oportunidad de empresarios dispuestos a afrontar los retos que las nuevas tecnología proponen.

8. Se propone en la circular restricciones a la operación de los RPAS en Colombia, la primera es no superar los $25 \mathrm{Kg}$ de peso al despegue y la segunda es no arrojar objeto alguno durante el vuelo. Estas dos limitaciones restringen el uso de las plataformas aéreas en lo relativo a la aspersión limitada de productos agroquímicos, solidos pulverizados, semisólidos, emulsiones, líquidos y polinización dirigida, etc. En AP la administración localizada de estos productos proporciona una indudable ventaja económica y una indiscutible ventaja ambiental ecológica, en áreas rurales de bajo tráfico aéreo y con baja población. Los aspectos relacionados con una norma flexible a la medida de los diferentes ámbitos agroecológicos son necesarias.

Por lo anterior expuesto, se plantea que:

- Existen suficientes argumentos para considerar que la Circular reglamentaria 002 del 2015 de la UAEAC, es inaplicable para la agricultura de precisión y para otras aplicaciones ambientales y geográficas.

Se recomienda que:

- La UAEAC reconsidere la norma, pues ella no contempla los aspectos aquí descritos y que por medio de audiencias públicas con amplia participación se establezca una reglamentación que con temple las validas aspiraciones de los diferentes usuarios de 
las plataformas aerotransportadas de baja altura y se le confiera a las instituciones de investigación un régimen especial con flexibilidad sobre todo para continuar con las investigaciones en alturas de vuelo y rango de operación de los sensores aerotransportados de baja altura y alta resolución (SABAAR).

- Considerar que las plataformas aerotransportadas de investigación estén sujetas a permiso especial de la dirección de servicios a la navegación aérea, en tanto que ellas portan sensores para la teledetección

- necesarios para la investigación básica y aplicada, que es fundamental para establecer cuál es la altu- ra optima de vuelo y el rango de operación, para que a los sensores a bordo les sea posible observar los diferentes fenómenos que afectan la agricultura, tales como plagas y enfermedades, deficiencias nutricionales, infestación de malezas, vulnerabilidad y riesgo de inundaciones y fuego, ordenamiento territorial a escala predial. Esto es necesario porque en un país con una mega diversidad de paisajes geomorfológicos las condiciones de operación de las plataformas aerotransportadas deben ser y tener consideraciones ecos regionales y ello debe ser tenido en cuenta para reglamentar la actividad. 